\title{
Clíticos pronominais em gêneros jornalísticos escritos das variedades europeia e brasileira do português: (re)discutindo a atuação dos fatores condicionantes linguísticos
}

\author{
Caroline Carnielli Biazolli \\ Universidade Estadual Paulista "Júlio de Mesquita Filho" (UNESP) \\ Araraquara, São Paulo, Brasil \\ carolbiazolli@yahoo.com.br
}

DOI: $\underline{\text { http://dx.doi.org/10.21165/el.v45i1.707 }}$

\begin{abstract}
Resumo
Fundamentado na Teoria da Variação e Mudança Linguísticas, este artigo pretende examinar a variação na posição de clíticos pronominais adjungidos a complexos verbais, sempre que presentes nos gêneros jornalísticos carta do leitor e editorial. Para a coleta dos dados, utilizamse os jornais Público e $O$ Estado de São Paulo, referentes respectivamente ao português europeu e ao português brasileiro, produzidos no período de 2001 a 2010. Deve-se verificar como as variantes previstas se distribuem nesses textos e se há consideráveis diferenças entre os dados provenientes de cada uma das variedades aqui estudadas. Para isso, neste momento, avalia-se a atuação de determinados fatores condicionantes linguísticos potencialmente responsáveis por essa variação - a saber: tipo de clítico, formas verbais do primeiro e do segundo verbo do complexo e tipo de complexo verbal.
\end{abstract}

Palavras-chave: clíticos pronominais; complexos verbais; fatores condicionantes linguísticos; gêneros jornalísticos; variação linguística.

Pronominal Clitics in Written Journalistic Genres in European and Brazilian Portuguese: (Re)discussing the Role of Linguistic Constraints

\begin{abstract}
Based on the Theory of Language Variation and Change, this paper intends to examine the variation in the position of pronominal clitics connected to verbal complexes in the written journalistic genres known as readers' letter and editorial. The newspapers used for data collection are Público and $O$ Estado de São Paulo, referring to Portuguese used in Portugal and Brazil, respectively. They were both published from 2001 to 2010 . This study intends to verify how both variants are distributed in these texts and if there are considerable differences between the collected data from each analyzed variety. For this purpose, this article evaluates the role of certain linguistic constraints potentially responsible for this variation, namely type of clitic, verb forms of the first and second verb of the complex, and type of verbal complex.
\end{abstract}

Keywords: pronominal clitics; verbal complexes; linguistic constraints; journalistic genres; linguistic variation.

\section{Palavras iniciais}

Observa-se, aqui, um fenômeno que desde o século XIX tem sido muito discutido no Brasil e em Portugal, destacando-se, atualmente, como um dos assuntos mais focalizados pelos estudiosos da língua (MATTOS E SILVA, 2004), a saber: a posição dos clíticos pronominais. Tem-se que, adjuntos a um único verbo, os clíticos 
podem ocupar as posições proclítica, mesoclítica ou enclítica e, adjacentes a um complexo verbal, podem se alternar nas posições pré-complexo verbal (pré-CV), intracomplexo verbal (intra-CV), ligados ao primeiro ou ao segundo verbo, ou pós-complexo verbal (pós-CV).

Sob aportes teórico-metodológicos diversificados, encontra-se na Linguística uma vasta bibliografia a respeito dos pronomes clíticos (PAGOTTO, 1992; MARTINS, 1994; LOBO, 2001; VIEIRA, 2002; SCHEI, 2003; GALVES; BRITTO; PAIXÃO DE SOUSA, 2005; SARAIVA, 2008; BIAZOLLI, 2010; PETERSON, 2010; dentre tantos outros trabalhos). Trata-se de um tópico que desperta bastante interesse por reunir características articuláveis nos diferentes níveis da língua e, ainda, referindo-se propriamente à colocação pronominal, por apontar notáveis diferenças entre as variedades do português, em especial entre o português europeu (doravante, PE) e o português brasileiro (doravante, PB).

Neste artigo, pautando-se nas premissas da Teoria da Variação e Mudança Linguísticas (WEINREICH; LABOV; HERZOG, 2006[1968]; LABOV, 1982, 2008[1972]), verifica-se, de modo preliminar, a variação na posição de clíticos pronominais, quando adjacentes a complexos verbais, presentes em textos escritos referentes aos gêneros textuais jornalísticos carta do leitor e editorial. As produções analisadas, provenientes do jornal português Público e do periódico brasileiro $O$ Estado de São Paulo, pertencem aos primeiros anos do século XXI, de 2001 a 2010. Deve-se sublinhar que o presente trabalho se insere em um estudo descritivo-comparativo sobre a cliticização pronominal do $\mathrm{PE}$ e do $\mathrm{PB}$, ainda em andamento, que se fundamenta também em conceitos relacionados a estilo, gêneros textuais, modalidades de uso da língua e normas linguísticas ${ }^{1}$.

A decisão pelos gêneros do domínio jornalístico, tomados como fonte de coleta dos dados, refere-se ao fato de, por um lado, tais gêneros ainda não terem sido suficientemente explorados pela Linguística, e, por outro, de acordo com Berlinck e Biazolli (2011), pelos textos que os representam, através da linguagem, abarcarem o que há de maior prestígio sociocultural, ao mesmo tempo que também podem veicular distintas variantes linguísticas não padrão.

Neste momento, através da análise de determinados fatores condicionantes linguísticos possivelmente/potencialmente responsáveis pela variação quanto à colocação desses pronomes no PE e no PB, acredita-se no registro de uma expressiva diferenciação entre os dados obtidos da amostra portuguesa e os da brasileira, uma vez que a posição dos clíticos relacionados a complexos verbais é tida como um ponto evidente de usos diversos entre as variedades consideradas.

$\mathrm{Na}$ sequência, depois dessas palavras iniciais, detalham-se (i) a noção de complexo verbal adotada neste estudo, (ii) os procedimentos metodológicos seguidos, revelando-se a constituição dos corpora, as variantes e as variáveis independentes

\footnotetext{
1 Reconhece-se a pluralidade dialetal presente em cada uma das variedades da língua portuguesa selecionada para este estudo. Desse modo, embora sejam utilizadas as denominações PE e PB, faz-se um retrato dessas regiões fundamentado em dados extraídos principalmente das variedades lisboeta e paulistana, considerando-se, de modo geral, as cidades nas quais são publicados os periódicos examinados em questão - Público, de Lisboa, e O Estado de São Paulo, de São Paulo. Ademais, ressaltase que as análises aqui apresentadas se referem a dois gêneros textuais jornalísticos em particular, refletindo o comportamento do clítico pronominal em um contexto específico.
} 
linguísticas trabalhadas, e (iii) os primeiros resultados fornecidos pelo programa estatístico Goldvarb X (SANKOFF et al., 2005). Para finalizar, apresentam-se certas conclusões e a lista das obras mencionadas.

\section{Delimitando-se um complexo verbal}

Os complexos verbais, nesta investigação, referem-se a construções constituídas por dois verbos (verbo (semi)auxiliar + verbo principal na forma não finita) ${ }^{2}$, havendo, entre eles, certo grau de interação sintático-semântica. Internamente coesos, esses grupos verbais funcionam como se fossem um único verbo, cabendo ao verbo pleno a componente descritiva, incluindo a seleção dos argumentos, e, ao primeiro verbo, a expressão dos valores de tempo, modo e aspecto. Nas orações em que estão presentes, são os complexos verbais como um todo, e não apenas o verbo principal, que funcionam como núcleo semântico do sintagma verbal e da própria oração (RAPOSO, 2013). Nas estruturas aqui consideradas, o pronome clítico pode se alternar em qualquer uma das três posições (pré, intra ou pós-verbal), mantendo-se o mesmo valor de verdade.

Para se chegar a uma noção adequada sobre o que é e como se caracteriza um complexo verbal, deve-se certamente refletir sobre o caráter (semi)auxiliar de sua forma finita. Na direção de observações mais criteriosas a respeito da auxiliaridade, recorre-se, então, à caracterização desse assunto na linguística contemporânea. Entretanto, deve-se dizer que, mesmo com o estabelecimento de propriedades explícitas de auxiliaridade, pautadas em aspectos sintático-semânticos e elencadas igualmente em grande parte dos trabalhos que versam sobre o tema, ainda há certas divergências em relação a uma lista final de verbos auxiliares, quando examinado mais de um estudo linguístico (RAPOSO, 2013).

É pertinente que se entenda que a auxiliaridade é um fenômeno gradual, havendo os verbos tipicamente auxiliares e, entre estes e os verbos principais (não auxiliares), um grupo de verbos com comportamento oscilante, os semiauxiliares.

Um critério semântico bastante defendido para comprovar a auxiliaridade de um verbo, como dito acima, é o fato de itens verbais desse tipo não selecionarem argumentos. Por não possuírem significado lexical, tais formas não têm propriedades de seleção semântica. Desse modo, "o SN que ocorre com a relação gramatical de sujeito em frases com verbos auxiliares faz parte do complexo predicativo organizado em torno do verbo auxiliado" (DUARTE, 2003[1983], p. 303).

No trabalho de Gonçalves e Costa (2002), as autoras investigam estes critérios de auxiliaridade: (i) impossibilidade de coocorrência com orações completivas finitas; (ii) impossibilidade de substituição do domínio encaixado por uma forma pronominal demonstrativa; (iii) impossibilidade de coocorrência de duas posições de sujeito; (iv) passivas encaixadas sem alteração do significado básico da ativa correspondente; (v) impossibilidade de ocorrência do operador de negação frásica no domínio não finito; (vi) ocorrência dos complementos pronominalizados (cliticizados) em adjacência ao verbo auxiliar; (vii) coocorrência com qualquer classe aspectual de predicados verbais;

\footnotetext{
2 Os complexos com mais de dois verbos (isto é, aqueles que apresentam mais de um verbo (semi)auxiliar) foram excluídos das análises por aparecerem de modo reduzido - 12 dados no PE e somente 5 no $\mathrm{PB}$.
} 
e (viii) impossibilidade de ocorrência de modificadores temporais que afetem apenas a interpretação do domínio não finito.

Baseando-se no cumprimento de todas essas propriedades, as autoras certificam os verbos ter e haver, seguidos do particípio, como os auxiliares "puros" do português. $\mathrm{Na}$ sequência, encontram-se os semiauxiliares, verbos que respondem a alguns, mas não a todos, desses critérios de auxiliaridade. Para ordená-los, Gonçalves e Costa (2002) sugerem uma escala, conforme o grau de aproximação de cada verbo aos auxiliares, resumida deste modo:

1. Ser passivo: difere dos auxiliares por permitir a substituição do complemento por um clítico demonstrativo;

2. Verbos temporais (ir, vir, haver (de)): diferem dos auxiliares por permitirem a manutenção dos complementos cliticizados do verbo no Infinitivo em adjacência a este verbo;

3. Verbos modais poder e dever e aspectuais seguidos de $a$ : diferem dos auxiliares por permitirem a ocorrência (i) do operador de negação no complemento infinitivo e (ii) dos complementos cliticizados do verbo no Infinitivo em adjacência a este verbo; alguns destes verbos impõem restrições quanto à classe aspectual a que pertence o predicado verbal do complemento;

4. Verbo modal ter (de) e verbos aspectuais seguidos de de (e também para e por): diferem dos auxiliares por (i) não permitirem a extracção de complementos cliticizados do domínio infinitivo para o domínio matriz e (ii) limitarem a classe aspectual dos predicados verbais com que se combinam. (GONÇALVES; COSTA, 2002, p. 98, grifo original)

As estudiosas ainda mencionam que alguns verbos plenos (a saber, conseguir, tentar, querer, mandar, ver, etc.), em determinados contextos, comportam-se como auxiliares. Essa prática, segundo Gonçalves e Costa (2002), justifica-se pelo complemento frásico infinitivo ser, temporalmente, dependente da frase matriz, formando uma única cadeia temporal.

Mediante as considerações feitas sobre o tratamento da auxiliaridade, percebe-se um número variado de estruturas que podem integrar um complexo verbal sob uma forma finita simples. Dessa maneira, como mencionado anteriormente, neste estudo, os grupos verbais analisados não são só aqueles formados por verbos reconhecidamente auxiliares, mas, também, são os complexos constituídos por itens verbais mais ou menos próximos do polo da auxiliaridade, respectivamente, os semiauxiliares e os verbos com certa independência semântica (por exemplo: querer, tentar, ousar, etc.).

\section{Procedimentos metodológicos}

Volta-se, agora, à descrição dos corpora selecionados como matrizes da extração dos dados, detalhando-se, na sequência, as variantes correspondentes à variável dependente examinada e os grupos de fatores linguísticos considerados, uma vez que se trata de um trabalho inserido no âmbito da Sociolinguística Variacionista.

\section{Constituição dos corpora}

Fez-se necessário que os materiais analisados do PE e do PB fossem equivalentes, dado que o estudo em questão, além de descritivo, caracteriza-se como comparativo. Desse modo, julgou-se mais eficiente a formação dos corpora português e 
brasileiro a partir de conjuntos uniformes em extensão (número de palavras). Assim, para cada gênero apreciado, em cada uma das variedades, reuniu-se um montante em torno de trinta e cinco mil (35.000) palavras - conforme as descrições feitas subsequentemente ${ }^{3}$.

Tabela 1. Informações referentes ao gênero carta do leitor: números de cartas e de palavras

\begin{tabular}{l|c|c}
\hline \multicolumn{3}{c}{ CARTA DO LEITOR } \\
\hline & Número de textos & Número de palavras \\
\hline PE - Público & 105 & 34.474 \\
\hline PB - O Estado de São Paulo & 227 & 34.473 \\
\hline Total & 332 & 68.947 \\
\hline
\end{tabular}

Tabela 2. Informações referentes ao gênero editorial: números de editoriais e de palavras

\begin{tabular}{l|c|c}
\hline \multicolumn{3}{|c}{ EDITORIAL } \\
\hline PE - Público & Número de textos & Número de palavras \\
\hline PB - O Estado de São Paulo & 66 & 35.489 \\
\hline Total & 52 & 35.713 \\
\hline
\end{tabular}

Reportando-se às cartas, no início, foram encontradas 135 no periódico lisboeta e 758 no jornal paulistano. Desses totais, excluíram-se os textos em que apareciam explicitamente a ocupação social do enunciador ou, ainda, quando este era estrangeiro. No primeiro caso, acredita-se que, ao explicitar a posição ocupada, o autor do texto poderia apresentar uma monitoração ainda mais consciente de seus usos linguísticos; já, no segundo, a exclusão das cartas se refere ao fato de que autores estrangeiros não possuem o português como a sua primeira língua. Os números, então, passaram para 108 e 689. Das 108 cartas portuguesas, os clíticos pronominais estavam presentes em 105 e, das 689 cartas brasileiras, tais pronomes foram registrados em 366 textos. O passo seguinte, para que as amostras do PE e do PB permanecessem equilibradas, foi o recorte no número de cartas provenientes do periódico O Estado de São Paulo, utilizando-se como critério, na medida do possível, a manutenção daquelas com o maior número de linhas. Desse modo, chegou-se aos números apresentados na tabela 1 .

Para finalizar, no que diz respeito aos editoriais, em uma primeira seleção, foram verificados 127 textos, sendo 67 representativos do PE e 60 do PB. Verificou-se que, a partir de novembro de 2009, os jornais portugueses passaram a publicar dois editoriais por exemplar. Além disso, quanto aos textos portugueses, em 1 editorial coletado não se registrou a presença de pronome clítico. Em relação aos editoriais do diário $O$ Estado de São Paulo, 6 foram selecionados para cada ano averiguado. Em todos, assinalaram-se construções com pronomes átonos, no entanto, preservando-se a ideia de corpora equivalentes para as duas variedades em questão, reduziu-se aleatoriamente o número final de editoriais brasileiros postos sob exame - cf. tabela 2.

\footnotetext{
${ }^{3}$ Sobre os jornais examinados - Público e O Estado de São Paulo -, convém citar que os dois possuem certas características semelhantes, tais como a política editorial, a grande circulação em termos de nação e o público-alvo. Dentro do espaço temporal considerado, de 2001 a 2010, investigaram-se seis exemplares de cada um deles por ano, escolhidos aleatoriamente.
} 


\section{Variantes em contextos de complexos verbais}

Admite-se que a regra variável da colocação dos pronomes átonos em contextos de adjacência a complexos verbais é eneária, dado que permite quatro possibilidades de posicionamento do pronome. São elas:

(i) clítico em posição pré-CV (cl V1 V2):

(01) É que perguntar não ofende e sempre gostaria de saber como se vai fazendo a política de museus no longínquo reino da Dinamarca. (PE, gênero carta, 2008)

(ii) clítico em posição intra-CV-enclítico a $V 1-(\mathrm{V} 1-\mathrm{cl} \mathrm{v} 2)$ :

(02) Existem claramente factores de persistência da pobreza, que se reflectem em ciclos de vida ou que são transmitidos intergerações, mas deve-se falar igualmente na persistência da pobreza enquanto fenómeno social. (PE, gênero editorial, 2004)

(iii) clítico em posição intra-CV-enclítico a V1 ou proclítico a V2 - (V1 cl V2):

(03) Espero que a prefeita esteja se preparando para limpar todos os rios de São Paulo, pois aqueles que não querem ou não podem pagar a taxa passarão a jogar lixos nos rios, como se faz com lixo não coletado pela Prefeitura (sofás velhos, pneus). (PB, gênero carta, 2003)

(iv) clítico em posição pós-CV(V1 V2-cl):

(04) Mas alguns empresários brasileiros - poucos, é verdade - também apoiam essa insensatez. Talvez os novos desmandos cometidos na Venezuela possam mostrar-lhes o tamanho desse erro. (PB, gênero editorial, 07/06/2002)

Norteia-se esta pesquisa pela presença do hífen para marcar ligações enclíticas, relacionadas a V1 ou a V2 - assim como destacado em Pagotto (1992), Schei (2003) e Peterson (2010), dentre outros trabalhos. Reconhece-se a possibilidade de os periódicos examinados conterem equívocos de natureza gráfica, inserindo-se ou eliminando-se um hífen por descuido, todavia, acredita-se que constatar a presença ou a ausência do traço de união, fator que confirma a coexistência de variantes distintas, é um dos meios que confere objetividade ao tratamento das ocorrências. 


\section{Variáveis independentes linguísticas}

seguir:

Controlam-se, neste artigo, os seguintes grupos de fatores, dispostos no quadro a

Quadro 1. Distribuição geral dos grupos de fatores, de natureza interna, analisados

\begin{tabular}{|c|c|}
\hline GRUPOS DE FATORES & FATORES \\
\hline (i) Tipo de clítico & $\begin{array}{l}\text { Me; te; o(s)/a(s) e formas variantes (FV); lhe(s); } \\
\text { se; nos e vos. }\end{array}$ \\
\hline (ii) Forma do primeiro verbo do complexo & $\begin{array}{l}\text { Presente, pretéritos e futuros do Indicativo; } \\
\text { presente, pretérito e futuro do Subjuntivo; } \\
\text { Imperativos e Formas Nominais. }\end{array}$ \\
\hline (iii) Forma do segundo verbo do complexo & Infinitivo; gerúndio e particípio. \\
\hline (iv) Tipo de complexo verbal & 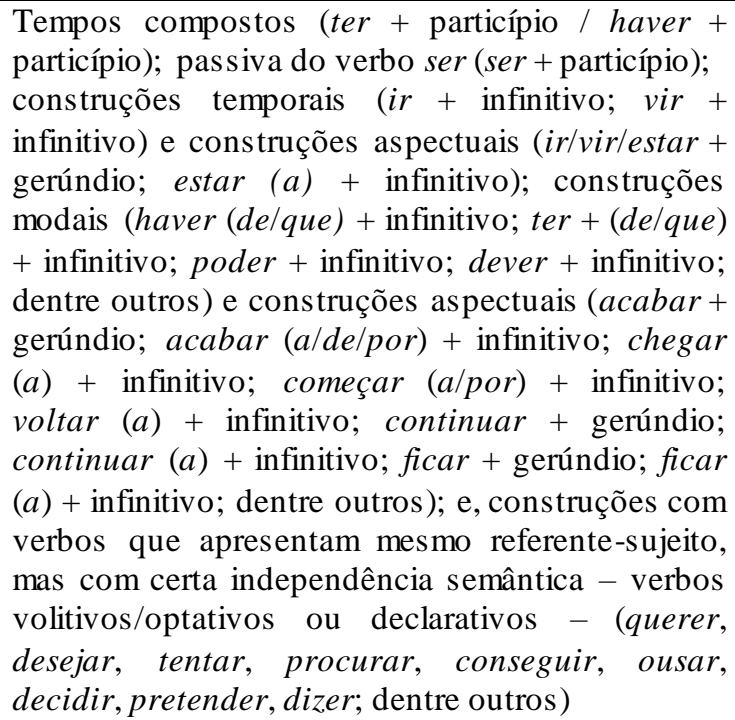 \\
\hline
\end{tabular}

\section{Resultados preliminares}

Os resultados apresentados, conforme já descrito, provêm da análise de dados do periódico impresso Público, para a variedade do PE, e do diário O Estado de São Paulo, para a variedade do PB. A quantificação, composta de análises univariadas, valeu-se do programa Goldvarb X (SANKOFF et al., 2005).

$\mathrm{Na}$ sequência, relacionam-se os dados encontrados aos gêneros textuais investigados - carta do leitor e editorial -, focando-se na atuação dos fatores condicionantes linguísticos aqui considerados. $\mathrm{Na}$ tabela seguinte, mostra-se a distribuição geral das ocorrências de clíticos pronominais adjungidos a complexos verbais, nas variedades do PE e do PB, segundo o gênero jornalístico escolhido.

Tabela 3. Distribuição geral das ocorrências de clíticos pronominais nas variedades do PE e do PB, de acordo com o gênero textual jornalístico examinado

\begin{tabular}{l|c|c|c}
\hline & PE & PB & Total \\
\hline Cartado Leitor & 102 & 78 & 180 \\
\hline Editorial & 105 & 54 & 159 \\
\hline Total & 207 & 132 & 339 \\
\hline
\end{tabular}




\section{Clíticos pronominais adjungidos a complexos verbais no gênero carta do leitor}

Para este gênero, foram organizados um conjunto com 102 clíticos retirados do $\mathrm{PE}$ e outro, referente ao $\mathrm{PB}$, com 78 pronomes. Segundo as variantes aqui trabalhadas, notou-se, na variedade portuguesa, que 64 pronomes estavam na posição pré-CV, 16 na posição intra-CV, V1-cl V2, 4 na posição intra-CV, V1 cl V2, e 18 na posição pós-CV. No universo das cartas brasileiras, 26 clíticos ocuparam a posição pré-CV, 5 a posição intra-CV, V1-cl V2, 20 a posição intra-CV, V1 cl V2, e 27 a posição após o grupo verbal.

O gráfico seguinte revela os percentuais de cada alternativa de colocação pronominal conforme a variedade do português contemplada.

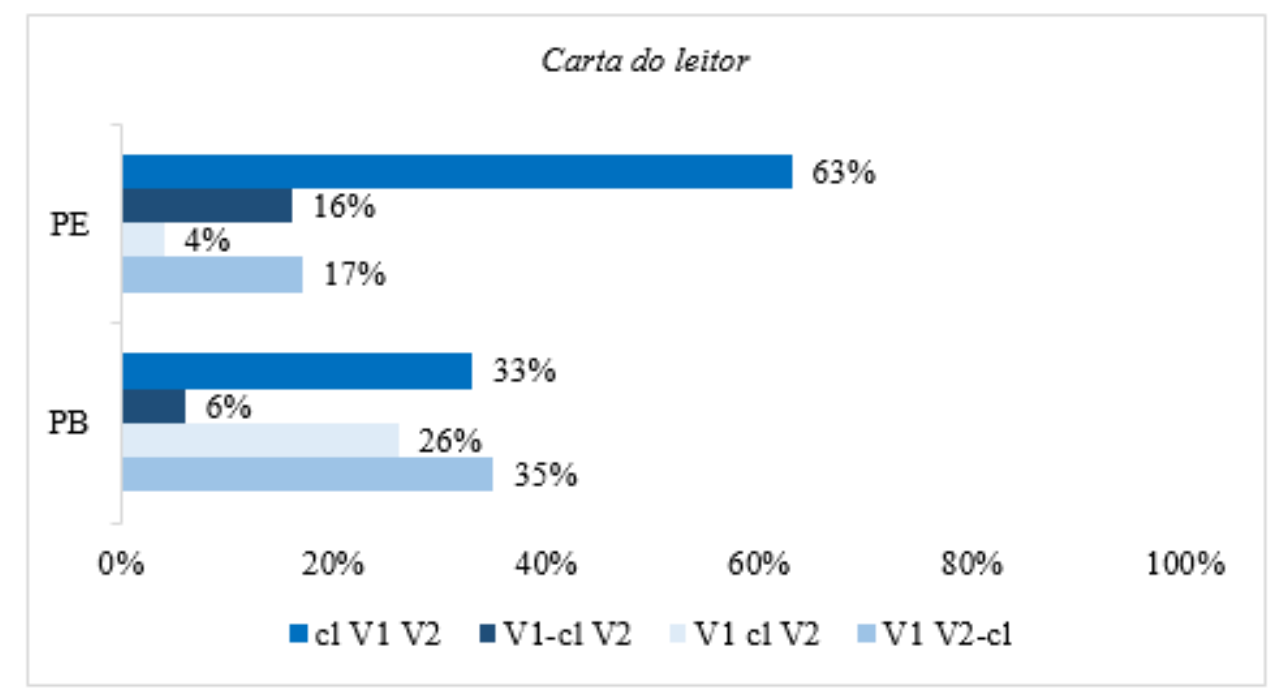

Gráfico 1. Distribuição geral das ocorrências das posições pré, intra e pós-complexos verbais no gênero carta, nas variedades do PE e do PB

Aos $4 \%$ marcados no PE, no que se refere à posição V1 cl V2, deve-se indicar que representam dados com a presença de elementos intervenientes entre os verbos do complexo, diferentemente do que foi visto no PB - cf. exemplos (05) e (06).

(05) A poucos dias das legislativas, é amargo verificar o pouco que se falou de política, de projectos, de ideias, da forma como temos de nos preparar para enfrentar um futuro difícil no meio de uma crise global que veio juntar-se à já nossa crise local. (PE, gênero carta, 2009)

(06) Nessa mesma época os sindicatos e a UNE não podiam se manifestar contra o governo. (PB, gênero carta, 2008)

No PE, enquanto não se registraram os pronomes te e vos, recolheram-se 62 pronomes se, 12 nos, 10 me, $10 o(s) / a(s)$ e FV e 8 lhe $(s)$. No material do $\mathrm{PB}$, o te e o vos também não apareceram, observando-se 44 pronomes se, $16 o(s) / a(s)$ e FV, 8 nos, 6 lhe $(s)$ e 4 me.

As tabelas 4 e 5 especificam os números absolutos e os percentuais de colocação pronominal em contextos de complexos verbais, consoante o tipo de clítico, nas variedades do $\mathrm{PE}$ e do $\mathrm{PB}$. 
Tabela 4. Número de ocorrências e percentuais de clíticos pronominais, de acordo com o tipo de clítico, no gênero carta, na variedade do $\mathrm{PE}$

\begin{tabular}{c|c|c|c|c|c|c|c|c|c|c}
\hline Tipo de clítico & \multicolumn{2}{|c|}{$\mathrm{cl} \mathrm{V1} \mathrm{V2}$} & \multicolumn{2}{c|}{ V1-cl V2 } & \multicolumn{2}{c|}{ V1 cl V2 } & \multicolumn{2}{c|}{ V1 V2-cl } & \multicolumn{2}{c}{ Total } \\
\hline se & 42 & $68 \%$ & 11 & $18 \%$ & 0 & $0 \%$ & 9 & $14 \%$ & 62 & $67 \%$ \\
\hline nos & 8 & $68 \%$ & 1 & $8 \%$ & 2 & $16 \%$ & 1 & $8 \%$ & 12 & $13 \%$ \\
\hline me & 3 & $30 \%$ & 3 & $30 \%$ & 0 & $0 \%$ & 4 & $40 \%$ & 10 & $10 \%$ \\
\hline o(s)/a(s) e FV & 5 & $50 \%$ & 0 & $0 \%$ & 2 & $20 \%$ & 3 & $30 \%$ & 10 & $10 \%$ \\
\hline Total & 58 & $62 \%$ & 15 & $16 \%$ & 4 & $4 \%$ & 17 & $18 \%$ & N- 94 \\
\hline
\end{tabular}

Tabela 5. Número de ocorrências e percentuais de clíticos pronominais, de acordo com o tipo de clítico, no gênero carta, na variedade do $\mathrm{PB}$

\begin{tabular}{c|c|c|c|c|c|c|c|c|c|c}
\hline Tipo de clítico & \multicolumn{2}{|c|}{ cl V1 V2 } & \multicolumn{2}{c|}{ V1-cl V2 } & \multicolumn{2}{c|}{ V1 cl V2 } & \multicolumn{2}{c|}{ V1 V2-cl } & \multicolumn{2}{c}{ Total } \\
\hline se & 17 & $39 \%$ & 4 & $9 \%$ & 16 & $36 \%$ & 7 & $16 \%$ & 44 & $73 \%$ \\
\hline o(s)/a(s) e FV & 1 & $6 \%$ & 0 & $0 \%$ & 0 & $0 \%$ & 15 & $94 \%$ & 16 & $27 \%$ \\
\hline Total & 18 & $30 \%$ & 4 & $6 \%$ & 16 & $27 \%$ & 22 & $37 \%$ & $\mathrm{~N}-60$ \\
\hline
\end{tabular}

Salienta-se, nas duas variedades, a recorrência do pronome se e, ainda, destacase o comportamento do clítico $o(s) / a(s)$ e $\mathrm{FV}$ na posição intra-CV. No $\mathrm{PB}$, são inexistentes registros com esse tipo de pronome nessa posição, devido possivelmente à fragilidade fônica que apresenta. No PE, por sua vez, os dois únicos dados observados com o clítico $o$ apareceram na posição V1 cl V2 com a presença da preposição de entre os verbos do complexo.

No que diz respeito à análise da variável forma do primeiro verbo do complexo, os resultados por si sós confirmam que as formas verbais, na presente ocasião, não agem sobre a colocação pronominal, verificando-se de modo geral, por exemplo, índices de cada variante não tão discordantes dos índices totais do fenômeno, no PE e no PB cf. as próximas tabelas.

Tabela 6. Número de ocorrências e percentuais de clíticos pronominais, de acordo com a forma verbal de V1, no gênero carta, na variedade do $\mathrm{PE}$

\begin{tabular}{c|c|c|c|c|c|c|c|c|c|c}
\hline F. verbal de V1 & \multicolumn{2}{|c|}{$\mathrm{cl}$ V1 V2 } & \multicolumn{2}{c|}{ V1-cl V2 } & \multicolumn{2}{c|}{ V1 cl V2 } & \multicolumn{2}{c|}{ V1 V2-cl } & \multicolumn{2}{c}{ Total } \\
\hline Pres. Ind. & 40 & $71 \%$ & 7 & $13 \%$ & 3 & $5 \%$ & 6 & $11 \%$ & 56 & $68 \%$ \\
\hline Pret. Perf. Ind. & 4 & $25 \%$ & 6 & $37,5 \%$ & 0 & $0 \%$ & 6 & $37,5 \%$ & 16 & $20 \%$ \\
\hline Infinitivo & 6 & $60 \%$ & 3 & $30 \%$ & 0 & $0 \%$ & 1 & $10 \%$ & 10 & $12 \%$ \\
\hline Total & 50 & $61 \%$ & 16 & $19 \%$ & 3 & $4 \%$ & 13 & $16 \%$ & N- 82 \\
\hline
\end{tabular}

Tabela 7. Número de ocorrências e percentuais de clíticos pronominais, de acordo com a forma verbal de V1, no gênero carta, na variedade do PB

\begin{tabular}{c|c|c|c|c|c|c|c|c|c|c}
\hline F. verbal de V1 & \multicolumn{2}{|c|}{$\mathrm{cl} \mathrm{V1} \mathrm{V2}$} & \multicolumn{2}{c|}{ V1-c1 V2 } & \multicolumn{2}{c|}{ V1 cl V2 } & \multicolumn{2}{c|}{ V1 V2-cl } & \multicolumn{2}{c}{ Total } \\
\hline Pres. Ind. & 18 & $38 \%$ & 4 & $8 \%$ & 10 & $21 \%$ & 16 & $33 \%$ & 48 & $83 \%$ \\
\hline Fut. Pret. Ind. & 3 & $30 \%$ & 0 & $0 \%$ & 1 & $10 \%$ & 6 & $60 \%$ & 10 & $17 \%$ \\
\hline Total & 21 & $36 \%$ & 4 & $7 \%$ & 11 & $19 \%$ & 22 & $38 \%$ & N- 58 \\
\hline
\end{tabular}

Referente à variável forma do segundo verbo do complexo, com o Infinitivo, visualiza-se uma maior variação entre as quatro variantes, nas cartas das duas localidades. Quanto ao Particípio, no $\mathrm{PE}$, focando-se na posição pós-CV, a inexistência de dados com o pronome posposto ao segundo verbo pode refletir, de fato, um traço

4 Para a composição das tabelas, doravante, células que apresentaram menos de 10 dados foram desprezadas. 
dessa variedade, o qual a tradição gramatical descreveu adequadamente, ainda que tenha o apresentado como uma prescrição, uma vez que dita a obrigatoriedade de não se deslocar o pronome átono para depois de formas participiais. Com o Gerúndio, no PB, vê-se a próclise ao grupo verbal, em conformidade com o que é prescrito nas gramáticas, já que é bem provável que tais dados tragam em suas orações elementos proclisadores. No entanto, observam-se também casos de clíticos entre o verbo auxiliar e o verbo pleno na forma gerundiva, atestando-se a produtividade da variante V1 cl V2 no português daqui. As tabelas 8 e 9 elucidam por completo esses apontamentos.

Tabela 8. Número de ocorrências e percentuais de clíticos pronominais, de acordo com a forma verbal de V2, no gênero carta, na variedade do $\mathrm{PE}$

\begin{tabular}{c|c|c|c|c|c|c|c|c|c|c}
\hline F. verbal de V2 & \multicolumn{2}{|c|}{$\mathrm{cl} \mathrm{V1} \mathrm{V2}$} & \multicolumn{2}{c|}{ V1-cl V2 } & \multicolumn{2}{c|}{ V1 cl V2 } & \multicolumn{2}{c|}{ V1 V2-cl } & \multicolumn{2}{c}{ Total } \\
\hline Infinitivo & 51 & $63 \%$ & 8 & $10 \%$ & 4 & $5 \%$ & 18 & $22 \%$ & 81 & $84 \%$ \\
\hline Particípio & 8 & $53 \%$ & 7 & $47 \%$ & 0 & $0 \%$ & 0 & $0 \%$ & 15 & $16 \%$ \\
\hline Total & 59 & $61 \%$ & 15 & $16 \%$ & 4 & $4 \%$ & 18 & $19 \%$ & $\mathrm{~N}-96$ \\
\hline
\end{tabular}

Tabela 9. Número de ocorrências e percentuais de clíticos pronominais, de acordo com a forma verbal de V2, no gênero carta, na variedade do PB

\begin{tabular}{c|c|c|c|c|c|c|c|c|c|c}
\hline F. verbal de V2 & \multicolumn{2}{|c|}{$\mathrm{cl}$ V1 V2 } & \multicolumn{2}{c|}{ V1-cl V2 } & \multicolumn{2}{c|}{ V1 cl V2 } & \multicolumn{2}{c|}{ V1 V2-cl } & \multicolumn{2}{c}{ Total } \\
\hline Infinitivo & 17 & $29 \%$ & 2 & $3 \%$ & 14 & $23 \%$ & 27 & $45 \%$ & 60 & $85 \%$ \\
\hline Gerúndio & 5 & $46 \%$ & 2 & $18 \%$ & 4 & $36 \%$ & 0 & $0 \%$ & 11 & $15 \%$ \\
\hline Total & 22 & $31 \%$ & 4 & $6 \%$ & 18 & $25 \%$ & 27 & $38 \%$ & N- 71 \\
\hline
\end{tabular}

À variável tipo de complexo verbal atribuem-se as informações das tabelas $10 \mathrm{e}$ 11 , relacionadas, nessa devida ordem, ao $\mathrm{PE}$ e ao $\mathrm{PB}$.

Adjacentes a Construções temporais + construções aspectuais, no PE, os clíticos pronominais se posicionaram preferencialmente antes do complexo verbal (78\%), ao mesmo tempo que, no $\mathrm{PB}$, com essas mesmas estruturas, os pronomes se dividiram de modo idêntico (32\%) entre as posições pré-CV, intra-CV, V1 cl V2, e pós$\mathrm{CV}$ - cf. tabelas dispostas na sequência.

Tabela 10. Número de ocorrências e percentuais de clíticos pronominais, de acordo com o tipo de complexo verbal, no gênero carta, na variedade do $\mathrm{PE}$

\begin{tabular}{c|c|c|c|c|c|c|c|c|c|c}
\hline Tipo de CV & \multicolumn{2}{|c|}{$\mathrm{cl} \mathrm{V1}$ V2 } & \multicolumn{2}{|c|}{ V1-cl V2 } & \multicolumn{2}{|c|}{ V1 cl V2 } & \multicolumn{2}{|c|}{ V1 V2-cl } & \multicolumn{2}{c}{ Total } \\
\hline $\begin{array}{c}\text { Construções temporais + } \\
\text { construções aspectuais }\end{array}$ & 14 & $78 \%$ & 3 & $17 \%$ & 0 & $0 \%$ & 1 & $5 \%$ & 18 & $21 \%$ \\
\hline $\begin{array}{c}\text { Construções modais + } \\
\text { construções aspectuais }\end{array}$ & 30 & $57 \%$ & 5 & $9 \%$ & 4 & $8 \%$ & 14 & $26 \%$ & 53 & $62 \%$ \\
\hline $\begin{array}{c}\text { Construções com verbos } \\
\text { volitivos/ optativos ou } \\
\text { declarativos }\end{array}$ & 11 & $73 \%$ & 1 & $7 \%$ & 0 & $0 \%$ & 3 & $20 \%$ & 15 & $17 \%$ \\
\hline Total & 55 & $64 \%$ & 9 & $10 \%$ & 4 & $5 \%$ & 18 & $21 \%$ & \multicolumn{2}{c|}{$\mathrm{N}-86$} \\
\hline
\end{tabular}


Tabela 11. Número de ocorrências e percentuais de clíticos pronominais, de acordo com o tipo de complexo verbal, no gênero carta, na variedade do PB

\begin{tabular}{c|c|c|c|c|c|c|c|c|c|c}
\hline Tipo de CV & \multicolumn{2}{|c|}{$\mathrm{cl} \mathrm{V1} \mathrm{V2}$} & \multicolumn{2}{c|}{ V1-cl V2 } & \multicolumn{2}{c|}{ V1 $\mathrm{cl}$ V2 } & \multicolumn{2}{c|}{ V1 V2-cl } & \multicolumn{2}{c}{ Total } \\
\hline $\begin{array}{c}\text { Construções temporais + } \\
\text { construções aspectuais }\end{array}$ & 6 & $32 \%$ & 1 & $4 \%$ & 6 & $32 \%$ & 6 & $32 \%$ & 19 & $27 \%$ \\
\hline $\begin{array}{c}\text { Construções modais + } \\
\text { construções aspectuais }\end{array}$ & 11 & $28 \%$ & 2 & $5 \%$ & 10 & $26 \%$ & 16 & $41 \%$ & 39 & $56 \%$ \\
\hline $\begin{array}{c}\text { Construções com verbos } \\
\text { volitivos/ optativos ou } \\
\text { declarativos }\end{array}$ & 5 & $42 \%$ & 0 & $0 \%$ & 2 & $16 \%$ & 5 & $42 \%$ & 12 & $17 \%$ \\
\hline Total & 22 & $31 \%$ & 3 & $4 \%$ & 18 & $26 \%$ & 27 & $39 \%$ & \multicolumn{2}{c|}{$\mathrm{N}-70$} \\
\hline
\end{tabular}

No contexto Construções modais + construções aspectuais, vale assinalar que, em ambas as variedades, os resultados para todas as variantes foram os que mais se assemelharam aos percentuais gerais da colocação pronominal nas cartas, revelando-se, assim, que essas estruturas possivelmente não atuam sobre a ordem do pronome. Quanto às Construções com verbos volitivos/optativos ou declarativos, destaca-se, outra vez, o predomínio da posição pré-CV no PE e os índices semelhantes das posições pré e pós-complexos verbais no PB. Deve-se mencionar, ainda, quanto aos poucos dados das posições intra-CV, V1 cl V2, e intra-CV, V1-cl V2, respectivamente no PE e no PB, o fato de assinalarem a não produtividade dessas variantes nas cartas das variedades estudadas.

\section{Clíticos pronominais adjungidos a complexos verbais no gênero editorial}

Em relação ao gênero editorial, dispôs-se de um total de 159 dados (105 portugueses e 54 brasileiros). Do $\mathrm{PE}$, foram extraídos 50 pronomes à esquerda do complexo verbal, 20 pronomes na posição intra-CV, 10 na posição V1-cl V2 e 10 na posição $\mathrm{V} 1 \mathrm{cl} \mathrm{V} 2$, e 35 pronomes na posição pós-CV. Nos editoriais do $\mathrm{PB}$, reuniram-se 25 clíticos na posição pré-CV, 8 na posição $\mathrm{V} 1-\mathrm{cl} \mathrm{V} 2,11$ entre os verbos do complexo, na posição $\mathrm{V} 1 \mathrm{cl}$ V2, e 10 na posição pós-CV - cf. gráfico 2.

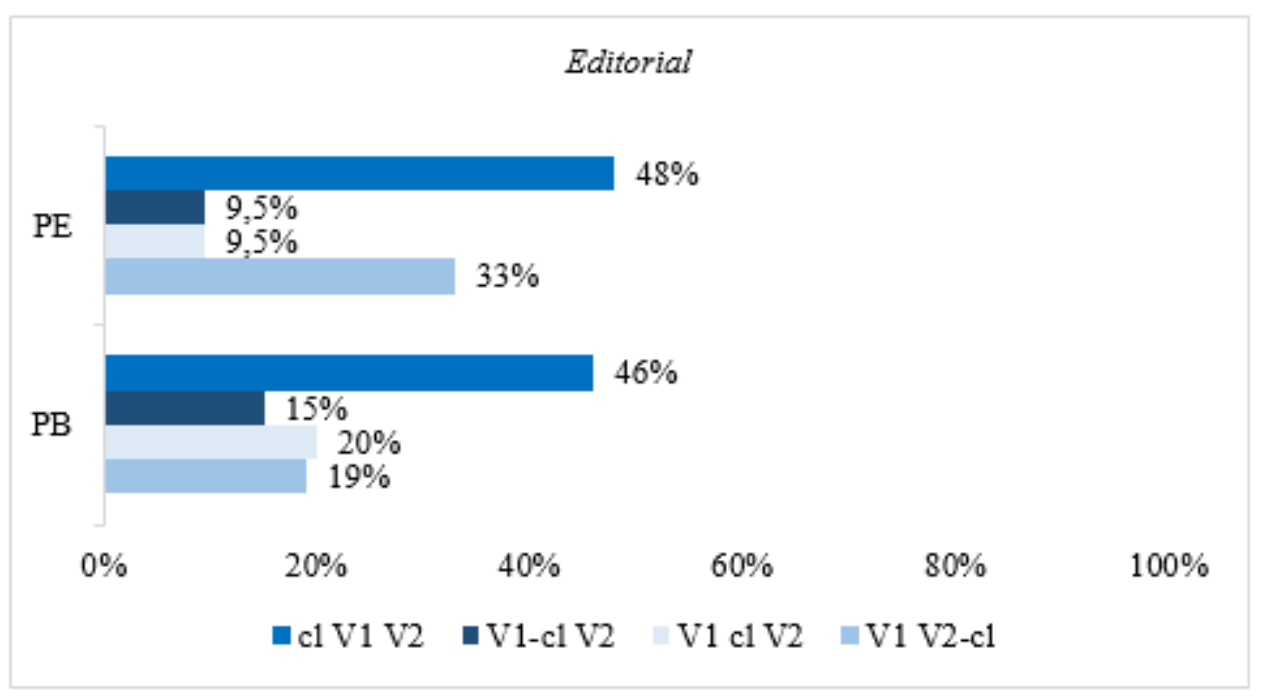

Gráfico 2. Distribuição geral das ocorrências das posições pré, intra e pós -complexos verbais no gênero editorial, nas variedades do $\mathrm{PE}$ e do $\mathrm{PB}$ 
Sobre o tipo de clítico, encontraram-se, nos editoriais portugueses, 78 pronomes se, $15 o(s) / a(s)$ e FV, 6 nos e 6 lhe(s). Não se manifestaram os clíticos me, te e vos. Dentre os dados brasileiros, por sua vez, avistaram-se apenas os clíticos se (45 dados), $o(s) / a(s)$ e FV (5 dados) e lhe(s) (4 dados). As tabelas 12 e 13 relacionam as alternativas de colocação pronominal às formas dos pronomes clíticos.

Tabela 12. Número de ocorrências e percentuais de clíticos pronominais, de acordo com o tipo de clítico, no gênero editorial, na variedade do $\mathrm{PE}$

\begin{tabular}{c|c|c|c|c|c|c|c|c|c|c}
\hline Tipo de clítico & \multicolumn{2}{|c|}{$\mathrm{cl} \mathrm{V1} \mathrm{V2}$} & \multicolumn{2}{c|}{ V1-cl V2 } & \multicolumn{2}{c|}{ V1 cl V2 } & \multicolumn{2}{c|}{ V1 V2-cl } & \multicolumn{2}{c}{ Total } \\
\hline se & 41 & $52 \%$ & 10 & $13 \%$ & 3 & $4 \%$ & 24 & $31 \%$ & 78 & $84 \%$ \\
\hline $\mathrm{o}(\mathrm{s}) / \mathrm{a}(\mathrm{s}) \mathrm{e} \mathrm{FV}$ & 3 & $20 \%$ & 0 & $0 \%$ & 4 & $27 \%$ & 8 & $53 \%$ & 15 & $16 \%$ \\
\hline Total & 44 & $47 \%$ & 10 & $11 \%$ & 7 & $8 \%$ & 32 & $34 \%$ & $\mathrm{~N}-93$ \\
\hline
\end{tabular}

Tabela 13. Número de ocorrências e percentuais de clíticos pronominais, de acordo com o tipo de clítico, no gênero editorial, na variedade do PB

\begin{tabular}{|c|c|c|c|c|c|c|c|c|c|c|}
\hline Tipo de clítico & \multicolumn{2}{|c|}{$\mathrm{cl} \mathrm{V1} \mathrm{V2}$} & \multicolumn{2}{|c|}{ V1-cl V2 } & \multicolumn{2}{|c|}{$\mathrm{V} 1 \mathrm{cl} \mathrm{V} 2$} & \multicolumn{2}{|c|}{ V1 V2-cl } & \multicolumn{2}{|c|}{ Total } \\
\hline $\mathrm{se}$ & 20 & $45 \%$ & 8 & $18 \%$ & 11 & $24 \%$ & 6 & $13 \%$ & 45 & $100 \%$ \\
\hline $\begin{array}{l}\text { Frequência } \\
\text { geral }^{5}\end{array}$ & \multicolumn{2}{|c|}{$46 \%$} & \multicolumn{2}{|c|}{$15 \%$} & \multicolumn{2}{|c|}{$20 \%$} & \multicolumn{2}{|c|}{$19 \%$} & \multicolumn{2}{|c|}{$100 \%$} \\
\hline
\end{tabular}

Quanto à posição intra-CV, V1 cl V2, no $\mathrm{PE}$, realça-se que os dados com se e $o(s) / a(s)$ e FV se encontraram todos com a presença de um elemento interveniente entre os verbos do complexo. Ainda em relação ao clítico $o(s) / a(s)$ e $\mathrm{FV}$, nos editoriais portugueses, a falta de registros da sua colocação na posição intra-CV, V1-cl V2, afirma, mais uma vez, a improdutividade desse pronome entre formas verbais, dadas as suas particularidades fônicas.

Os casos com o se, no $\mathrm{PB}$, essencialmente aqueles posicionados entre o verbo auxiliar e o verbo pleno, poderão ser mais bem compreendidos numa etapa posterior, quando também analisada a variável função do clítico.

As tabelas seguintes, e os seus respectivos resultados, referem-se à forma do primeiro verbo do complexo.

Tabela 14. Número de ocorrências e percentuais de clíticos pronominais, de acordo com a forma verbal de V1, no gênero editorial, na variedade do PE

\begin{tabular}{c|c|c|c|c|c|c|c|c|c|c}
\hline F. verbal de V1 & \multicolumn{2}{|c|}{ c1 V1 V2 } & \multicolumn{2}{|c|}{ V1-cl V2 } & \multicolumn{2}{c|}{ V1 cl V2 } & \multicolumn{2}{c|}{ V1 V2-cl } & \multicolumn{2}{c}{ Total } \\
\hline Pres. Ind. & 26 & $55 \%$ & 4 & $8,5 \%$ & 4 & $8,5 \%$ & 13 & $28 \%$ & 47 & $57 \%$ \\
\hline Pret. Imp. Ind. & 9 & $69 \%$ & 0 & $0 \%$ & 1 & $8 \%$ & 3 & $23 \%$ & 13 & $16 \%$ \\
\hline Pres. Subj. & 5 & $46 \%$ & 0 & $0 \%$ & 2 & $18 \%$ & 4 & $36 \%$ & 11 & $13,5 \%$ \\
\hline Infinitivo & 6 & $55 \%$ & 1 & $9 \%$ & 1 & $9 \%$ & 3 & $27 \%$ & 11 & $13,5 \%$ \\
\hline Total & 46 & $56 \%$ & 5 & $6 \%$ & 8 & $10 \%$ & 23 & $28 \%$ & $\mathrm{~N}-82$ \\
\hline
\end{tabular}

Tabela 15. Número de ocorrências e percentuais de clíticos pronominais, de acordo com a forma verbal de V1, no gênero editorial, na variedade do PB

\begin{tabular}{c|c|c|c|c|c|c|c|c|c|c}
\hline F. verbal de V1 & \multicolumn{2}{|c|}{ c1 V1 V2 } & \multicolumn{2}{c|}{ V1-c1 V2 } & \multicolumn{2}{c|}{ V1 cl V2 } & \multicolumn{2}{c|}{ V1 V2-cl } & \multicolumn{2}{c}{ Total } \\
\hline Pres. Ind. & 12 & $48 \%$ & 7 & $28 \%$ & 3 & $12 \%$ & 3 & $12 \%$ & 25 & $71 \%$ \\
\hline Fut. Pres. Ind. & 2 & $20 \%$ & 0 & $0 \%$ & 4 & $40 \%$ & 4 & $40 \%$ & 10 & $29 \%$ \\
\hline Total & 14 & $40 \%$ & 7 & $20 \%$ & 7 & $20 \%$ & 7 & $20 \%$ & N- 35 \\
\hline
\end{tabular}

\footnotetext{
${ }^{5}$ Nas tabelas que trazem apenas os resultados de um dos fatores do grupo analisado, decide-se apontar as
} frequências gerais de colocação de cada variante, a fim de que possíveis comparações sejam facilitadas. 
Assim como demonstrado no gênero jornalístico carta do leitor, a forma verbal do primeiro verbo do complexo parece não influenciar isoladamente a colocação pronominal.

$\mathrm{Na}$ sequência, descreve-se a variável forma verbal do segundo verbo do complexo.

Tabela 16. Número de ocorrências e percentuais de clíticos pronominais, de acordo com a forma verbal de $\mathrm{V} 2$, no gênero editorial, na variedade do $\mathrm{PE}$

\begin{tabular}{c|c|c|c|c|c|c|c|c|c|c}
\hline F. verbal de V2 & \multicolumn{2}{|c|}{$\mathrm{cl}$ V1 V2 } & \multicolumn{2}{c|}{ V1-cl V2 } & \multicolumn{2}{c|}{ V1 c1 V2 } & \multicolumn{2}{c|}{ V1 V2-cl } & \multicolumn{2}{|c}{ Total } \\
\hline Infinitivo & 35 & $40 \%$ & 9 & $9 \%$ & 10 & $11 \%$ & 35 & $40 \%$ & 89 & $86 \%$ \\
\hline Particípio & 13 & $93 \%$ & 1 & $7 \%$ & 0 & $0 \%$ & 0 & $0 \%$ & 14 & $14 \%$ \\
\hline Total & 48 & $46 \%$ & 10 & $10 \%$ & 10 & $10 \%$ & 35 & $34 \%$ & \multicolumn{2}{|c|}{$\mathrm{N}-103$} \\
\hline
\end{tabular}

Tabela 17. Número de ocorrências e percentuais de clíticos pronominais, de acordo com a forma verbal de V2, no gênero editorial, na variedade do PB

\begin{tabular}{|c|c|c|c|c|c|c|c|c|c|c|}
\hline F. verbal de V2 & \multicolumn{2}{|c|}{$\mathrm{cl} \mathrm{V1} \mathrm{V2}$} & \multicolumn{2}{|c|}{ V1-cl V2 } & \multicolumn{2}{|c|}{$\mathrm{V} 1 \mathrm{cl} \mathrm{V} 2$} & \multicolumn{2}{|c|}{ V1 V2-cl } & \multicolumn{2}{|c|}{ Total } \\
\hline Infinitivo & 18 & $41 \%$ & 7 & $16 \%$ & 9 & $20 \%$ & 10 & $23 \%$ & 44 & $100 \%$ \\
\hline $\begin{array}{c}\text { Frequência } \\
\text { geral }\end{array}$ & & & & & & & & & & $0 \%$ \\
\hline
\end{tabular}

Com a forma verbal infinitiva, no PE, destacaram-se os percentuais idênticos das posições pré-CV e pós- $\mathrm{CV}$ e, no $\mathrm{PB}$, houve certo equilibrio entre os índices das posições pré e pós-complexos verbais e entre as marcas alcançadas pelas posições intraCV. A atuação desta variável deve estar atrelada, indubitavelmente, também a outros grupos de fatores (ainda não investigados, neste momento).

Por fim, nas tabelas 18 e 19, organizam-se os resultados originários das análises do grupo tipo de complexo verbal.

Tabela 18. Número de ocorrências e percentuais de clíticos pronominais, de acordo com o tipo de complexo verbal, no gênero editorial, na variedade do PE

\begin{tabular}{c|c|c|c|c|c|c|c|c|c|c}
\hline Tipo de CV & \multicolumn{2}{|c|}{ cl V1 V2 } & \multicolumn{2}{|c|}{ V1-cl V2 } & \multicolumn{2}{c|}{ V1 cl V2 } & \multicolumn{2}{c|}{ V1 V2-cl } & \multicolumn{2}{|c}{ Total } \\
\hline Tempos compostos & 10 & $91 \%$ & 1 & $9 \%$ & 0 & $0 \%$ & 0 & $0 \%$ & 11 & $11 \%$ \\
\hline $\begin{array}{c}\text { Construções modais + } \\
\text { construções aspectuais }\end{array}$ & 24 & $33 \%$ & 9 & $13 \%$ & 10 & $14 \%$ & 29 & $40 \%$ & 72 & $75 \%$ \\
\hline $\begin{array}{c}\text { Construções com verbos } \\
\text { volitivos/optativos ou } \\
\text { declarativos }\end{array}$ & 7 & $54 \%$ & 0 & $0 \%$ & 0 & $0 \%$ & 6 & $46 \%$ & 13 & $14 \%$ \\
\hline Total & 41 & $43 \%$ & 10 & $10 \%$ & 10 & $10 \%$ & 35 & $37 \%$ & \multicolumn{2}{|c|}{$\mathrm{N}-96$} \\
\hline
\end{tabular}

Tabela 19. Número de ocorrências e percentuais de clíticos pronominais, de acordo com o tipo de complexo verbal, no gênero editorial, na variedade do PB

\begin{tabular}{c|c|c|c|c|c|c|c|c|c|c}
\hline Tipo de CV & \multicolumn{2}{|c|}{$\mathrm{cl}$ V1 V2 } & \multicolumn{2}{c|}{ V1-cl V2 } & \multicolumn{2}{c|}{ V1 cl V2 } & \multicolumn{2}{c|}{ V1 V2-cl } & \multicolumn{2}{c}{ Total } \\
\hline $\begin{array}{c}\text { Construções modais + } \\
\text { construçôes aspectuais }\end{array}$ & 11 & $34 \%$ & 7 & $21 \%$ & 6 & $18 \%$ & 9 & $27 \%$ & 33 & $77 \%$ \\
\hline $\begin{array}{c}\text { Construções com verbos } \\
\text { volitivos/ optativos ou } \\
\text { declarativos }\end{array}$ & & & & & & & & & & \\
\hline Total & 18 & $40 \%$ & 0 & $0 \%$ & 2 & $20 \%$ & 1 & $10 \%$ & 10 & $23 \%$ \\
\hline
\end{tabular}

A adjunção dos clíticos a Tempos compostos, no PE, conforme o previsto, confirmou a predominância das posições relacionadas ao verbo auxiliar. Nesses casos, 
como o verbo pleno se encontra na forma participial, seguindo as prescrições gramaticais, o clítico tende a se posicionar em próclise ou em ênclise a V1 - cf. exemplos em (07). Nos dados coletados, a posição cl V1 V2 foi realmente a mais significativa.

(07) (a) Nunca, desde que há registos de temperaturas na Rússia, se tinha visto um calor assim. (PE, gênero editorial, 2010)

(b) Curiosamente, a lei islâmica que dá cobertura a tão "modernas" separações é a mesma que em países como a Nigéria serve para condenar à morte uma mulher que ouse ter um filho (que não seja do ex-marido) após ter-se divorciado. (PE, gênero editorial, 2003)

Com as Construções modais + construções aspectuais, tanto no PE quanto no $\mathrm{PB}$, verificaram-se os pronomes distribuídos entre as quatro posições. Por outro lado, quanto às Construções com verbos volitivos/optativos ou declarativos, assim como nas cartas, no PE, viu-se a predileção pelas posições pré e pós-complexos verbais e, ainda, notou-se nos editoriais a inexistência de dados nas posição intra-CV. No PB, reafirmouse com essas estruturas a baixa produtividade da colocação pronominal entre os verbos do complexo.

\section{Palavras finais}

A partir dos resultados apresentados, ainda que incipientes, notou-se o distanciamento entre as realidades portuguesa e brasileira quando o assunto se refere à colocação pronominal, certificando-se a relevância de se investir em um estudo descritivo-comparativo entre as duas variedades.

Reconhece-se a necessidade de um refinamento dos dados obtidos até então; portanto, dando continuidade a este estudo, pretende-se ampliar a gama de fatores condicionantes linguísticos a ser examinada, objetivando-se futuramente a realização de cruzamentos envolvendo os grupos de fatores aqui já mencionados e aqueles que ainda serão trabalhados - tais como: (i) tipo de elemento (proclisador) que antecede o grupo cl V1 V2 ou V1-cl V2 ou V1 cl V2 ou V1 V2-cl; (ii) distância entre o elemento (proclisador) antecedente e o grupo cl V1 V2 ou V1-cl V2 ou V1 cl V2 ou V1 V2-cl, (iii) função do clítico; e (iv) tipo de elemento interveniente entre os verbos do complexo.

Desde já, entretanto, os comportamentos diferenciados de cada variante do fenômeno analisado puderam indicar não só motivos linguísticos para tais divergências, mas, também, aspectos relacionados à própria natureza do gênero jornalístico ao qual estavam vinculados, natureza esta que envolve aspectos situacionais de sua produção/recepção. Nessa direção, valida-se a pertinência de investigações que buscam desvendar as relações entre variação e mudança linguísticas e gêneros textuais, devendo o presente trabalho, em seguida, também se encaminhar a exames qualitativos de cada gênero jornalístico abordado, restringindo-se a considerações acerca de suas características situacionais.

Com esta discussão inicial, intentou-se colaborar com o profícuo debate, vigente na literatura linguística, sobre a posição dos clíticos pronominais e, de modo mais amplo, cooperar com a pesquisa sociolinguística desenvolvida em Portugal e no Brasil, acrescentando-se mais resultados à descrição dessas variedades e da língua portuguesa como um todo. 


\section{REFERÊNCIAS}

BERLINCK, R. de A.; BIAZOLLI, C. C. Clíticos e preposições: a norma e o 'normal' em jornais paulistas (1900 a 1915). Estudos Linguísticos, v. 40, n. 2, p. 850-863, 2011.

BIAZOLLI, C. C. Clíticos pronominais no português de São Paulo: 1880 a 1920 - uma análise sócio-histórico-linguística. 2010. 230 f. Dissertação (Mestrado em Linguística e Língua Portuguesa) - Faculdade de Ciências e Letras, Universidade Estadual Paulista, Araraquara.

DUARTE, I. Relações gramaticais, esquemas relacionais e ordem de palavras. In: MATEUS, M. H. M. et al. (Orgs.). Gramática da língua portuguesa. 6. ed. Lisboa: Caminho, 2003[1983]. p. 275-321.

GALVES, C.; BRITTO, H.; PAIXÃO DE SOUSA, M. C. The Change in Clitic Placement from Classical to Modern European Portuguese: Results from the Tycho Brahe Corpus. Journal of Portuguese Linguistics, v. 4, n. 1, p. 39-67, 2005.

GONÇALVES, A.; COSTA, T. da. (Auxiliar a) Compreender os verbos auxiliares: descrição e implicações para o ensino do português como língua materna. Lisboa: Colibri, 2002. 137 p.

LABOV, W. Padrões sociolinguísticos. São Paulo: Parábola, 2008[1972]. 392 p.

Building on Empirical Foundations. In: LEHMANN, W. P.; MALKIEL, Y. (Eds.). Perspectives on Historical Linguistics. Philadelphia: John Benjamins Publishing, 1982. p. 17-92.

LOBO, T. C. F. Para uma sociolinguística histórica do português no Brasil: edição filológica e análise linguística de cartas particulares do Recôncavo da Bahia, século XIX. 2001. 4 v. Tese (Doutorado em Filologia e Língua Portuguesa) - Faculdade de Filosofia, Letras e Ciências Humanas, Universidade de São Paulo, São Paulo.

MARTINS, A. M. Clíticos na história do português. 1994. 628 f. Tese (Doutorado em Linguística Portuguesa) - Faculdade de Letras, Universidade de Lisboa, Lisboa.

MATTOS E SILVA, R. V. Ensaios para uma sócio-história do português brasileiro. São Paulo: Parábola, 2004. 175 p.

PAGOTTO, E. G. A posição dos clíticos em português: um estudo diacrônico. 1992. 168 f. Dissertação (Mestrado em Linguística) - Instituto de Estudos da Linguagem, Universidade Estadual de Campinas, Campinas.

PETERSON, M. S. A ordem dos clíticos pronominais em lexias verbais simples e complexas em cartas de leitor: uma contribuição da Sociolinguística Variacionista. 2010. 210 f. Dissertação (Mestrado em Língua Portuguesa) - Faculdade de Letras, Universidade Federal do Rio de Janeiro, Rio de Janeiro.

RAPOSO, E. B. P. Verbos auxiliares. In: et al. (Orgs.). Gramática do português. v. II. Lisboa: Fundação Calouste Gulbenkian, 2013. p. 1221-1281.

SANKOFF, D. et al. GoldVarb $X$ : a variable rule application for Macintosh and Windows. 2005.2 Disponível em: <http://individual. utoronto.ca/tagliamonte/gold varb.html >. Acesso em: 09 fev. 2015.

SARAIVA, L. M. S. A colocação dos pronomes átonos na escrita culta do domínio jornalístico e nos inquéritos do Projeto NURC: uma análise contrastiva. 2008. $108 \mathrm{f}$. 
Dissertação (Mestrado em Linguística) - Faculdade de Letras, Universidade Federal de Minas Gerais, Belo Horizonte.

SCHEI, A. A colocação pronominal do português brasileiro: a língua literária contemporânea. São Paulo: Humanitas FFLCH/USP, 2003. 281 p.

VIEIRA, S. R. Colocação pronominal nas variedades européia, brasileira $e$ moçambicana: para a definição da natureza do clítico em português. 2002. 441 f. Tese (Doutorado em Língua Portuguesa) - Faculdade de Letras, Universidade Federal do Rio de Janeiro, Rio de Janeiro.

WEINREICH, V.; LABOV, W.; HERZOG, M. Fundamentos empíricos para uma teoria da mudança linguística. São Paulo: Parábola, 2006[1968]. 151 p.

Recebido em: 03/10/2015

Aprovado em: 08/01/2016 